\title{
0 papel do professor e do aluno numa abordagem experimental das ciências nos primeiros anos de escolaridade
}

Paulo Varela

Ana Patrícia Martins

\section{Resumo}

Este artigo resulta de um projeto de intervenção pedagógica, realizado no âmbito do 2 o ciclo de estudos conducente ao grau de Mestre em Educação Préescolar e Ensino do 10 Ciclo do Ensino Básico. Uma turma $(n=17)$ do 10 ano de escolaridade foi sujeita a uma prática de ensino experimental das Ciências. Esta prática implica renovados papéis do professor e do aluno. $O$ projeto adotou uma metodologia de investigação-ação e teve como objetivos: a) promover uma abordagem prática e experimental das ciências; b) descrever o processo de construção de significados científicos de alguns temas curriculares; c) caracterizar o papel do professor e do aluno, no contexto dessa prática. Após a observação participante, foram elaborados diários de aula, com base nos registos escritos e gravações áudio das aulas. A análise dos diários permitiu identificar um conjunto de categorias relativas ao papel do professor e dos alunos na abordagem das ciências promovida na sala de aula. O processo de construção de significados é ilustrado, através da análise do caso da "flutuação e afundamento de objetos em água".

Palavras-chave: ensino das ciências, papel do professor e do aluno.

\begin{abstract}
The role of the teacher and the student in an experimental science approach in the primary education

This paper reports the results of a pedagogical intervention project, conducted under the $2^{\text {nd }}$ cycle of studies leading to the Master's degree in Preschool and Primary Education. One first-grade class $(n=17)$ was subject to the experimental Science teaching practice, which implies renewed roles for the teacher and the student. The project relied on an action research methodology and aimed at: a) promoting a practical and experimental science approach; b) describing the process of construction of scientific meanings; c) characterizing the role of the teacher and the student in the context of this practice. At the end of each intervention period in the classroom, class diaries were elaborated with the field notes and audio recordings of the classes. Data analysis enabled the identification of a set of categories concerning the role of the teacher and the students within the classroom. The process of meaning construction is illustrated through the study of "floating and sinking objects in water".
\end{abstract}

Keywords: science teaching, role of the teacher and the student. 


\section{Introdução}

Em Portugal, as ciências físico-naturais estão incluídas no programa do 10 Ciclo do Ensino Básico na área curricular de "Estudo do Meio". Num dos blocos desta área, com a designação de "À Descoberta dos Materiais e Objetos", existe grande insistência em desenvolver nos alunos uma "permanente atitude de experimentação" na abordagem dos conteúdos que o integram, tais como: "realizar experiências com alguns materiais e objetos; realizar experiências com a água, som, ar, luz, ímanes, mecânica", etc... No bloco "À Descoberta do Ambiente Natural" encontramse expressões, como: "levantar questões, a procura de respostas através de experiências, pesquisas simples, observação direta, recolha de amostras, a utilização de instrumentos de observação e medida, como o termómetro, a bússola, a lupa, os binóculos..." (ME, 2004, p. 114). Nos princípios orientadores do programa existem ainda recomendações que sugerem aos professores a promoção de uma prática de ensino experimental e socioconstrutivista das ciências, devendo os alunos assumir um papel de "observadores ativos com capacidade para descobrir, investigar, experimentar e aprender" (ME, 2004, p. 112).

Porém, a experiência de mais de três décadas vem demonstrando que a introdução no programa curricular do 10 Ciclo do Ensino Básico de temas de ciências e de novas abordagens na construção dos saberes não têm produzido efeitos significativos na renovação das práticas pedagógicas e na, consequente, melhoria da qualidade das aprendizagens dos alunos (SÁ, 2002a). As crianças deste nível de ensino continuam a dispor de poucas oportunidades para desenvolver a "atitude experimental" anunciada na componente de ciências da área curricular de "Estudo do Meio" (ME, 2004), negligenciando-se importantes domínios de construção de saberes e de desenvolvimento de competências que atravessam as diferentes áreas curriculares (VARELA, 2012a). A importância educativa das ciências para as crianças é amplamente reconhecida. Harlen (2007) aponta as seguintes razões: a) contribui para que as crianças compreendam o mundo que as rodeia; b) desenvolve formas de descobrir, comprovar ideias e utilizar as evidências; c) desenvolve ideias que, em vez de obstaculizarem, ajudam a aprendizagem posterior de ciências; d) gera atitudes mais positivas e conscientes sobre a ciência, enquanto atividade humana. Apesar deste reconhecimento, o ensino das ciências, nos primeiros anos de escolaridade, continua a assumir, na prática dos professores, um caráter marginal, que enfatiza a transmissão e memorização da informação, e toda a retórica experimental e construtivista referida no programa de "Estudo do Meio" é sustentada pela exploração dos desenhos de objetos, animais e plantas contidos nos manuais escolares (SÁ e CARVALHO, 1997). Esta realidade está longe de corresponder a um problema específico do nosso país. Países como o Reino Unido e Estados Unidos, por exemplo, que, no início da década de 60, iniciaram avultados esforços de inovação no ensino das ciências, nos primeiros anos de escolaridade, depararam-se com o mesmo problema e continuam ainda hoje a conviver com ele, apesar dos progressos alcançados. Martínez e Díaz, reportando-se ao contexto educativo espanhol, salientam também que as orientações 
curriculares para a educação primária têm proposto um ensino das ciências mais inovador, baseado no papel ativo e construtivo do aluno. Contudo, a realidade de sala de aula é bem diferente: "os estudos e sondagens realizadas demonstram que ainda predomina um ensino das ciências transmissivo, baseado em explicações magistrais no quadro, no manual escolar e na resolução de problemas fechados de aplicação dos temas tratados" (2005, p. 243).

Ora, aprender e ensinar, longe de serem processos de reprodução e transmissão de conhecimentos, "implicam transformar a mente de quem aprende, que deve reconstruir a nível pessoal os produtos e processos culturais com o fim de apropriar-se deles" (POZO e CRESPO, 2006, p. 23). Significa, segundo Mauri (2001), que, para aprender, o aluno deve elaborar uma representação pessoal do conteúdo objeto de aprendizagem, o que requer necessariamente o seu envolvimento afetivo e cognitivo nas tarefas de aprendizagem. Essa elaboração não é realizada no vazio, pois o aluno é possuidor de um conjunto de experiências e conhecimentos prévios (DRIVER, et al,. 1999), que lhe permite interagir com o novo objeto ou conteúdo de conhecimento, atribuindo-Ihe determinados níveis de significação (MAURI, 2001). Porém, o aluno não é o único a intervir nesse processo: "os outros significantes, os agentes culturais, são peças imprescindíveis para a construção pessoal" (SOLÉ e COLL, 2001, p. 18). A atividade mental construtiva do aluno é assim mediada por fatores de natureza sociocultural (ALEMANY, 2000; MASON, 2007), através das relações sociais que estabelece com os outros e do uso de diversos instrumentos e artefactos culturais (VOSNIADOU, et al., 2005), como a linguagem (ALEMANY, 2000). Segundo Vygotsky (1998), a interação com outros alunos mais desenvolvidos, ou com o professor, e o domínio da linguagem são fatores determinantes na aprendizagem e no desenvolvimento do pensamento.

Neste sentido, promover uma abordagem de ensino experimental e socioconstrutivista das ciências exige, pois, ao professor e ao aluno, formas de atuação diferentes daquelas que tradicionalmente acorrem em sala de aula. (SÁ, 2002a; HARLEN, 2004). Os alunos devem ser envolvidos num processo genuíno de construção de significados científicos e desenvolvimento de recursos cognitivos, que se edificam na relação direta com os objetos concretos, com os seus pares e com o professor; manipulando esses objetos, refletindo sobre as observações e as ações que com eles realizam (SÁ e VARELA, 2007); verbalizando as suas ideias e estratégias, discutindoas e argumentando as diversas opiniões emergentes na turma (DOMÍNGUEZ e STIPCICH, 2009). A construção desses saberes exige ao professor que estimule e potencie a participação ativa dos alunos, valorizando genuinamente as suas ideias, promovendo a discussão e a argumentação em torno dessas ideias, num ambiente de colaboração (NAYLOR, et al., 2007). O professor deve ser capaz de formular questões que estimulem e desafiem o pensamento e a ação dos alunos, promovendo o confronto das suas próprias ideias entre si e com a evidência (HARLEN e QUALTER, 2005).

O professor desempenha um papel fundamental na estimulação e mediação das interações dos alunos, fornecendo a ajuda adequada para que estes possam autorregular a sua 
atividade cognitiva e escalar níveis de aprendizagem progressivamente mais elevados (CHIN, 2006; VARELA, 2012b; MOLENAAR, et al., 2011). Esta mediação feita pelo professor, para além de assumir o caráter de ajuda à atividade construtiva dos alunos, garante também "que as relações que eles estabelecem com o conteúdo a aprender sejam realmente relevantes e não arbitrárias; isto é, que tenham não apenas um valor individual-particular, mas também sociocultural" (MAURI, 2001, p. 89). Assim, todo o trabalho que os alunos vão realizando, na sala de aula, só acontece se houver uma atuação planificada e sistemática, por parte do professor, de forma a orientar os alunos, atender às suas necessidades e às intenções educativas que constam no currículo (ONRUBIA, 2001).

Segundo Harlen (2007), para que as crianças possam construir e desenvolver melhores ideias, acerca dos fenômenos físico-naturais, o professor deve ajudá-las: a) a tornarem-se conscientes das suas próprias ideias e das ideias dos outros para poderem compará-las e testá-las; b) a aplicarem tais ideias a determinadas situações ou problemas e a comprovarem a sua utilidade; c) a refletir criticamente sobre como as suas ideias devem ser utilizadas e comprovadas e a procurarem formas mais eficazes de realizar essas tarefas. A autora propõe um conjunto específico de ações a realizar pelo professor, numa abordagem experimental e investigativa das ciências com crianças: fornecer materiais e fontes de informação diversificadas; mostrar como se usam determinados instrumentos ou materiais de que necessitem na sua pesquisa; colocar questões abertas e centradas na criança para compreender as suas ideias atuais e como elas explicam os resultados encontrados: estimulá-las a sugerirem formas de testar as suas previsões, através da investigação ou da obtenção de evidências a partir de outras fontes; ajudá-las a planear as investigações para que as suas previsões possam ser corretamente testadas; ouvir e valorizar as suas ideias; colocar questões que estimulem as crianças a explicar as observações realizadas e as evidências obtidas; proporcionar oportunidades para que possam aprender de forma colaborativa; recolher informações sobre as aprendizagens que realizam, através da observação, do questionamento e da interação (HARLEN, 2004). Sá (2002a) sugere, também, o seguinte conjunto de ações, que o professor deverá desempenhar numa abordagem de ensino experimental das ciências nos primeiros anos de escolaridade: valorizar as ideias dos alunos; formular questões; conceder tempo; incentivar; procurar descodificar o significado das palavras dos alunos; estimular a discussão e a cooperação; dinamizar a discussão de grande grupo; promover sínteses após um processo de maturação cognitiva; promover a discussão horizontal; orientar os alunos através de questões, focalizando a atenção em materiais, no sentido de os induzir a planear e a executar procedimentos práticos/experimentais; estimular os alunos a apresentar as suas explicações, incitando-os à reflexão de grupo; focalizar a atenção da turma em boas ideias e fomentar a discussão das mesmas no sentido de as melhorar; ajudar e incentivar os alunos a realizar registos e relatórios, formulando questões para reflexão. 
Por seu lado, o aluno deve: envolver-se na exploração de materiais, objetos e fenômenos científicos; trabalhar em grupo com os seus colegas; colocar questões e reconhecer que as respostas, para essas questões, podem ser testadas ou investigadas; propor possíveis explicações para as observações realizadas; planear e realizar investigações para testar ideias, fazendo observações, medições ou usando outras formas de recolha de dados; registar os dados de forma adequada; explicar os resultados e relacioná-los com as ideias que foram testadas; comunicar o que realizaram, ouvir e partilhar ideias com os outros; refletir sobre o processo de investigação e sobre as mudanças que ocorreram nas suas ideias iniciais (HARLEN, 2004).

Sá e Varela (2004, 2007), sob a designação de "Ensino Experimental Reflexivo das Ciências", têm vindo a defender e a propor uma abordagem prática e experimental das ciências nos primeiros anos de escolaridade, orientada para a promoção de uma clara intencionalidade dos alunos, em termos de uma continuada atividade reflexiva sobre as suas ideias e ações. Segundo os autores, o ensino experimental das ciências pode ser entendido como um processo que interpela a mente das crianças, fazendo emergir o pensamento reflexivo e regulando a utilização da linguagem em interações recorrentes sujeito-objetos e sujeito-sujeitos, agindo o professor como mediador das interações, imbuído de forte intencionalidade pedagógica (SÁ, 2002a). Numa atmosfera de liberdade de comunicação e cooperação, propícia ao envolvimento afetivo e à expressão da criatividade, os alunos são estimulados a: a) explicitar as suas ideias e modos de pensar sobre questões, problemas e fenômenos; b) argumentar e contra-argumentar entre si e com o adulto, quanto ao fundamento das suas ideias, em contexto de pequeno e grande grupo; c) submeter as suas teorias pessoais à prova da evidência experimental; d) recorrer ao registo escrito ou icónico das observações e dados da evidência e das aprendizagens realizadas; e) avaliar criticamente o grau de conformidade das suas teorias, expectativas e previsões com as evidências; f) negociar as diferentes perspectivas pessoais emergentes no grupo, tendo em vista a construção de significados progressivamente mais enriquecidos e socialmente partilhados (SÁ e VARELA, 2004, 2007).

\section{Objetivos}

Este artigo resulta de um projeto de intervenção pedagógica de ciências, realizado no âmbito da Unidade Curricular de "Prática de Ensino Supervisionada", do 2o ano do ciclo de estudos conducente ao grau de Mestre em Educação Pré-escolar e 10 Ciclo do Ensino Básico. 0 projeto, supervisionado pelo primeiro autor deste artigo e implementado em sala de aula pelo segundo, teve como objetivos: a) promover, na abordagem de temas da área curricular de "Estudo do Meio" do 1ํ ano de escolaridade, uma prática de ensino experimental das ciências, baseada no papel ativo e construtivo do aluno, em contexto de interação social com os seus pares e com o professor; b) descrever e analisar o processo de construção de significados científicos, 
promovido em sala de aula; c) caracterizar o papel do professor e do aluno no processo de construção de significados científicos, no contexto dessa prática de ensino.

\section{Metodologia}

A intervenção pedagógica de ciências foi desenvolvida numa turma do 1o ano de escolaridade de uma escola do 1 ○ Ciclo do Ensino Básico, situada na periferia de cidade de Braga - Portugal. A turma era constituída por 17 alunos, 6 do sexo masculino e 11 do sexo feminino, com idades compreendidas entre os 5 e os 6 anos.

O projeto adotou uma abordagem de investigação-ação (LATORRE, 2004), aplicada ao estudo dos processos de ensino e aprendizagem em contexto de sala de aula (PÉREZ GÓMEZ, 2005). Cada ciclo interativo de investigação-ação correspondeu a uma aula que abordou temas de ciências da área curricular de "Estudo do Meio" do 1ㅇano de escolaridade. Foram lecionadas 5 aulas distribuídas ao longo de dois meses, num total de 10 horas de intervenção, conforme a tabela seguinte:

Tabela 1 - Tema abordado e duração das aulas.

\begin{tabular}{|l|l|}
\hline Tema da aula & Duração da aula \\
\hline Forma da Terra. O dia e a noite. & 2 Horas \\
\hline Movimento de rotação da Terra: alternância dia e noite. & 2.30 Horas \\
\hline Materiais sólidos solúveis e insolúveis em água. & 2.30 Horas \\
\hline Objetos que flutuam e objetos que se afundam & 2 Horas \\
\hline Avaliação das aprendizagens & 1 Horas \\
\hline Total & 10 Horas \\
\hline
\end{tabular}

Na sequência da observação participante em sala de aula, tendo por base as notas escritas e as gravações áudio efetuadas das aulas, foram elaborados 4 diários de aula. Estes, constituíram o principal método de registo de dados e, simultaneamente, uma estratégia de reflexão e modelação do processo de ensino-aprendizagem (SÁ, 2002b; ZABALZA, 2004). É com base na análise de um desses diários, sobre "a flutuação e afundamento dos objetos em água", que se descreve e analisa, neste artigo, o processo de construção ocorrido em sala de aula. Através de uma análise mais fina do conteúdo de todos os diários de aula elaborados, apresentam-se também as categorias identificadas relativas aos papéis desempenhados pelo professor e pelos alunos na prática de ensino experimental das ciências promovida na turma. 


\section{Análise dos resultados}

\section{Análise do diário de aula sobre a "flutuação e afundamento de objetos em água"}

Em pequenos grupos colaborativos, os alunos investigam a flutuação e afundamento de objetos em água. A aula inicia com as seguintes questões:

\section{A. O que quer dizer flutuar? E afundar?}

$\mathrm{A}_{1}$. As ideias iniciais dos alunos sobre os significados das palavras flutuar e afundar. Excerto do diário de aula:

As crianças rapidamente respondem, de acordo com as suas vivências $e$ experiências pessoais: "flutuar quer dizer que as coisas ficam em cima, a boiar..." (Pedro); "quando as coisas ficam a boiar na água, estão a flutuar" (Rafael); "quando estou a boiar na água da piscina também fico a flutuar"; "flutuar é ficar em cima" (Beatriz). "E o que quer dizer afundar?" - Pergunto. Várias crianças respondem em simultâneo e referem: "é estar no fundo"; "é como uma pedra que vai ao fundo" (Pedro); "se bater numa pedra, o barco racha e depois vai pró fundo" (Tiago); "mas tem que ser uma coisa pesada" Acrescenta a Ana Rita.

Os alunos recorrem às suas experiências do quotidiano para significar que um objeto está a flutuar quando ele "fica" ou "está em cima da água, a boiar", e afundar quando "vai ao fundo".

$A_{2}$. Representam as suas ideias através do desenho. Exemplos:
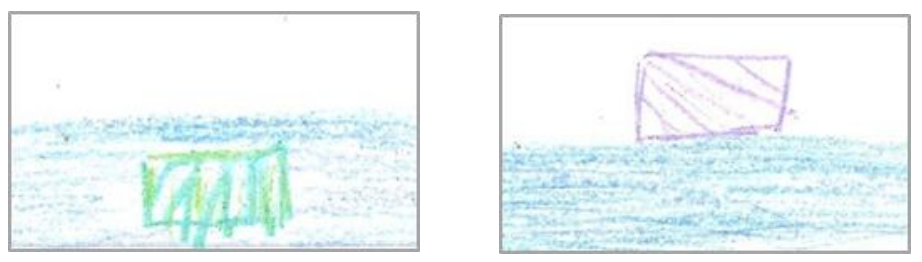

Figura 1 - Um objeto a afundar e outro a flutuar.

\section{B. O que acontecerá a esta rolha de cortiça se a colocarem na água? E a este parafuso?}

$\mathrm{B}_{1}$. Previsões acerca do comportamento de uma rolha e de um parafuso em água. Excerto do diário de aula:

Incentivo agora os grupos a pensar sobre o que acontecerá a uma rolha de cortiça e a um parafuso se os colocarem na água. Os grupos concordam com a ideia de que a rolha vai ficar em cima da água, a flutuar, e o parafuso vai ficar no fundo, justificando que "é mais pesado".

Os alunos são unânimes em prever que a rolha de cortiça flutua e o parafuso afunda. 


\section{0 que deverão fazer para verem se as vossas previsões estão corretas?}

Os alunos sugerem verificar experimentalmente: "temos que experimentar" (Ana Rita); "vamos fazer a experiência" (Marta).

$\mathrm{C}_{1}$. Os grupos testam as suas previsões.

As evidências produzidas pelos grupos são concordantes com as previsões elaboradas - a rolha flutua e o parafuso afunda.

\section{São introduzidos novos objetos.}

$\mathrm{D}_{1}$. Os alunos classificam os novos objetos com base em previsões. Excerto do diário de aula:

Forneço aos grupos mais 4 objetos: uma afia, um pedaço de madeira, um lápis e uma chave. "O que irá acontecer agora se colocarem estes objetos na água?" - Pergunto. Incentivo os alunos a formarem dois conjuntos, o dos objetos que flutuam $e$ o dos objetos que afundam. Rapidamente as crianças, entusiasmadas, começam a dialogar no interior dos grupos e a formar os conjuntos com base nas suas previsões: Grupo 1 - "afunda o parafuso e a madeira. Flutua a rolha, a chave e o lápis". O Pedro não concorda com os colegas, pois para ele o lápis não flutua. Grupo 2 - "flutua a rolha e o lápis $e$ afunda a chave, a madeira, o parafuso e a afia". Grupo 3 - "flutua o lápis e a rolha. A afia, o parafuso, a chave e a madeira vão ao fundo". Grupo 4 - "flutua a rolha e o lápis; afunda a madeira, a afia, a chave e o parafuso".

Os grupos formam dois conjuntos de objetos de acordo com as suas previsões e segundo o critério afunda/flutua. Três grupos apresentam previsões concordantes, quanto ao comportamento dos objetos na água, enquanto outro diverge dos anteriores ao incluir a chave no conjunto de objetos que irão flutuar. Verifica-se ainda que as previsões de todos os grupos contemplam o pedaço de madeira como um objeto que afunda.

$\mathrm{D}_{2}$. O que deverão fazer para saberem qual dos grupos tem razão?

Os grupos sugerem testar as suas previsões: "Temos que por na bacia"; "experimentar".

$\mathrm{D}_{3}$. Os grupos testam as suas previsões. Excerto do diário de aula:

Os grupos introduzem um objeto de cada vez numa bacia com água e observam o que acontece: "A madeira não afundou, está a flutuar" (Marta); "os outros acertamos todos" (Bianca); "o Pedro errou no lápis, porque ele disse que ia ao fundo mas ele flutua" (Tiago).

Os alunos confrontam as previsões com a evidência experimental. Os comentários dos alunos focalizam-se no comportamento dos objetos que contrariam as suas previsões, sendo com surpresa que verificam que o pedaço de madeira não afunda, como eles previam. 
$\mathrm{D}_{4}$. Os alunos elaboram dois conjuntos de objetos e realizam contagens.

Com base na evidência experimental, os alunos formam dois conjuntos de objetos, os que flutuaram e os que afundaram. Efetuam depois contagens dos elementos contidos em cada conjunto e estabelecem relações de grandeza entre os dois conjuntos.

\section{E.Por que razão alguns objetos flutuaram e outros afundaram?}

Excerto do diário de aula:

"Porque os que vão ao fundo são os mais pesados e os que flutuam são os mais leves" (Carlos). "As coisas levezinhas não vão pró fundo" (Marta). "Os mais "pesadinhos" vão ao fundo e os mais levezinhos flutuam" (Pedro). "Os pesadas vão ao fundo e os leves ficam em cima" (Mariana). "Se os objetos pesados vão ao fundo e os leves flutuam, será um navio, que flutua, leve e um grão de areia, que afunda, pesado? - Pergunto. As crianças ficam perplexas, sem avançarem qualquer explicação. "Será por ser leve que o navio flutua?" - Insisto. As crianças estão pensativas e algumas começam a admitir a possibilidade de os objetos pesados flutuarem: "o barco grande é pesado e flutua" (Beatriz). "Também há coisas grandes que flutuam, só que são muito pesados" (Carlos). "Um navio grande é pesado e não vai ao fundo" (Mariana). Outros argumentam que os barcos às vezes também vão ao fundo, quando têm avarias ou "buracos". "Mas, vocês estavam a dizer que as coisas pesadas iam ao fundo?" - Pergunto. "A água não tem tanta força como as coisas pesadas e depois vão ao fundo" (Ana Rita). "Eu já vi uma árvore grande e tábuas em cima da água" - refere o Renato.

As respostas começam por contemplam o "peso" como único fator explicativo dos fenômenos de flutuação e afundamento dos corpos em água. Trata-se de uma generalização baseada nas suas experiências do quotidiano. A questão introduzida, sobre o caso do navio e do grão de areia, eleva o nível de reflexão na turma. Todavia, não se esperava com ela que os alunos, face à complexidade dos fenômenos em causa e à sua maturidade intelectual, resolvessem o paradoxo que a questão suscita. Pretendeu-se apenas inquietar as suas mentes e provocar a tensão cognitiva geradora de ideias mais concordantes com o conhecimento que eles têm de que um navio flutua e é muito mais pesado do que um grão de areia. A reflexão promovida na turma provoca a abertura do pensamento dos alunos a novas possibilidades, começando alguns a sustentar a existência de objetos "grandes e pesados que flutuam". Há ainda quem relacione o fator peso dos objetos com a força da água para justificar que os objetos afundam, porque o seu peso é superior à força da água - impulsão: "A água não tem tanta força como as coisas pesadas e depois vão ao fundo". 


\section{F.A força que a água exerce nos objetos que nela são introduzidos}

$\mathrm{F}_{1}$. A água "empurra" os objetos para cima. Excerto do diário de aula:

Focalizo a atenção dos alunos na rolha de cortiça a flutuar e pergunto: "quando um objeto está a flutuar, quem é que o está a segurar?" As crianças referem que "é a água". Solicito a um elemento de cada grupo que pressione a rolha, na vertical, e pergunto: "O que está a acontecer?" "A água faz a rolha vir sempre para cima, quando a largo" (Bruno). "Se carregar na rolha, ela vai ao fundo e depois vem para cima. A água faz a rolha não ir para baixo" (Carolina). "Então, quem é que a empurra para cima?" - Pergunto. "É a água" (vários). "A água "empurra" a rolha, não a deixa ficar no fundo" (Rita). "A água faz força para a rolha vir para cima" (Marta).

Os alunos não manifestam dúvidas em afirmar que é a água que "segura" a rolha de cortiça a flutuar. Quando tentam colocar a rolha no fundo da água, sentem a força da água (impulsão) e visualizam o seu efeito sobre a rolha - a subida da rolha. Compreendem, então, que a rolha, um objeto flutuante, é "empurrada", de baixo para cima, pela ação da água.

$\mathrm{F}_{2}$. Será que a água só faz força nos objetos que flutuam? Excerto do diário de aula:

"Não, porque nesses a água tem mais força e puxa-os para cima" - responde prontamente a Marta. "Os que vão ao fundo têm mais força que a água" (Bruno). Outros pronunciam-se no mesmo sentido, existindo nesta altura na turma uma opinião favorável ao facto de a água exercer força, de baixo para cima, nos objetos nela introduzidos.

A ideia de que a ação da água se exerce sobre todo e qualquer objeto nela introduzida começa por ser referida por alguns alunos, pronunciando-se depois outros no mesmo sentido. Trata-se de uma generalização que está ao alcance de alunos de 5/6 anos de idade, recorrendo estes a explicações como a seguinte: "os que vão ao fundo têm mais força que a água".

\section{G. Registo das aprendizagens realizadas}

A aula termina com o registo das aprendizagens efetuadas. Os alunos registam individualmente na sua ficha de registos os materiais que flutuam e os que afundam. Excerto do tipo de registo: 


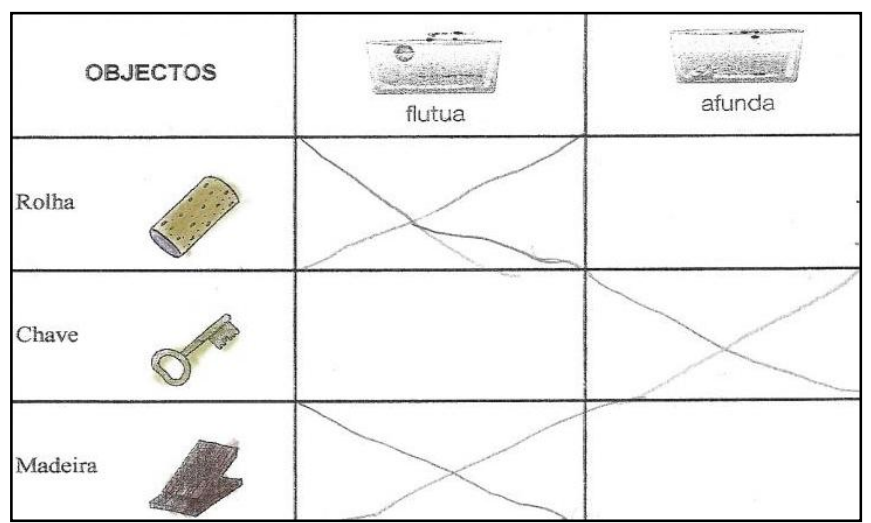

Figura 2 - Exemplo do tipo de registo efetuado pelos alunos.

\section{Análise interpretativa específica do conjunto dos diários de aula}

Procedeu-se a uma análise mais fina do conteúdo de todos os diários de aula, tendo agora em vista identificar categorias relativas às ações realizadas pelo professor e pelo aluno durante 0 processo de ensino-aprendizagem promovido em sala de aula.

\section{A. O Papel do professor no processo de ensino experimental das ciências.}

$\mathrm{A}_{1}$. Identificar as ideias iniciais dos alunos. Exemplos:

- "O que quer dizer a palavra flutuar?" (Diário de aula1).

- " "Como acham que será a forma da Terra?" (Diário de aula 3).

$\mathrm{A}_{2}$. Incentivar os alunos a elaborar previsões. Exemplos:

- "O que acontecerá a esta rolha de cortiça se a colocarem na água?" (Diário de aula 1).

- "O que irá acontecer se colocarem um pouco de açúcar num copo com água e agitarem?" (Diário de aula 2).

$A_{3}$. Proporcionar aos alunos a oportunidade de testar as suas previsões. Exemplo:

- "O que deverão fazer para verem se as vossas ideias estão corretas?" "Temos que experimentar; vamos fazer a experiência" (Diário de aula 1).

$A_{4}$. Fornecer os recursos materiais a serem utilizados pelos alunos. Exemplo:

- "Distribuo pelos grupos novos materiais: sal, um fragmento de rocha e um pouco de arroz. Após a livre exploração dos materiais, os grupos são solicitados a formar dois conjuntos: os materiais solúveis e os insolúveis" (Diário de aula 2).

A $_{5}$. Promover a colaboração e estimular a interação entre os alunos no interior dos grupos. Exemplo:

- Incentivo os elementos dos grupos a interagirem entre si, no sentido de refletirem e construírem uma explicação para o facto de o açúcar ter "desaparecido", quando o 
colocaram num copo com água. (...) Face a inexistência de explicações, por parte de alguns grupos, estimulo-os a refletir sobre a seguinte questão: "quando de manhã colocam açúcar no leite, como é que ele fica?" "O leite fica doce"; "o açúcar continua lá, porque faz ficar doce" (Rita); "fica docinho" (Matilde). "Então nesse caso, o açúcar terá saído do copo?" - Pergunto. "Não, porque o leite ficou docinho" (Matilde). "Então o que terá acontecido ao açúcar, quando o colocam no copo com água?" - Pergunto. "Ficou lá e fez a água doce" (Tiago); "o açúcar está lá, mas não se vê, porque está muito pequenino (Marta)" (Diário de aula 2).

$A_{6}$. Colocar questões que estimulem o pensamento dos alunos. Exemplos:

- "Será que a água só faz força nos objetos que flutuam?" (Diário de aula 1).

- "Se os objetos pesados vão ao fundo e os leves flutuam, será um navio, que flutua, leve e um grão de areia, que afunda, pesado? (Diário de aula 3).

$A_{7}$. Promover a comunicação à turma do trabalho desenvolvido pelos grupos. Exemplo:

- "Todos os grupos vão pensar e depois comunicar à turma o que acham que aconteceria se a Terra deixasse de girar e ficasse sempre parada" - Solicito. "Nuns países era sempre dia e noutros era sempre noite" (Inês); "onde desse o sol era sempre dia e as pessoas estavam sempre acordadas. Onde houvesse noite estavam sempre a dormir" (Pedro); "onde está noite as pessoas não podiam ir à escola" (Marta). "Não podiam sair de casa, porque estava sempre frio e noite" (Inês); "... e as plantas iam morrer" (Marta).

$A_{8}$. Avaliar as aprendizagens realizadas pelos alunos. Exemplo:
1. A Terra está parada em frente ao Sol.
2. É dia na parte da Terra que está virada para o Sol.
3. A Terra nunca para de rodar.
4. Quando a Terra roda vai ficando dia nuns sítios e noite noutros.
5. Quando é dia em Portugal noutros países é noite.
6. O sal dissolve-se na água.

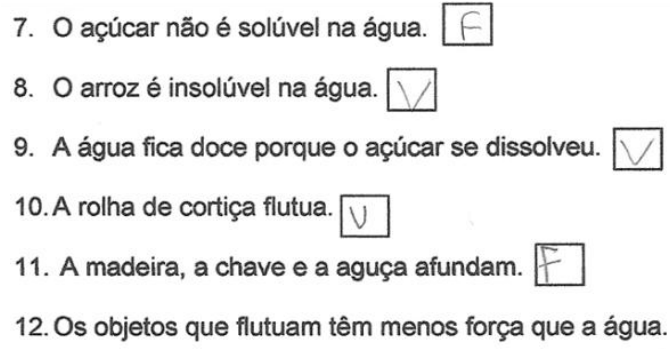

Figura 3-Exemplo de itens incluídos na ficha de avaliação das aprendizagens dos alunos.

\section{B. O Papel do aluno}

Da análise dos diários de aula foi também possível identificar as seguintes categorias, relativas ao papel do aluno:

$\mathrm{B}_{1}$. Comunicar ideias e modos de pensar. Exemplos: 
- "Flutuar quer dizer que as coisas ficam em cima, a boiar..." (Pedro); "quando as coisas ficam a boiar na água, estão a flutuar" (Rafael); ... (Diário de aula 1).

B2. Trabalhar em grupo, partilhando ideias e construindo o conhecimento em conjunto com os seus pares. Exemplo:

- Rapidamente as crianças, entusiasmadas, começam a dialogar no interior dos grupos e a formar os conjuntos com base nas suas previsões: Grupo 1 - "afunda o parafuso e a madeira. Flutua a rolha, a chave e o lápis". O Pedro não concorda com os colegas, pois para ele o lápis não flutua. (...) Grupo 4 - "flutua a rolha e o lápis; afunda a madeira, a afia, a chave e o parafuso" (Diário de aula 1).

B3. Elaborar e testar previsões. Exemplos:

- "Se colocarmos um pouco de açúcar num copo também com água e agitarmos, o que irá acontecer ao açúcar?" - Pergunto. Os vários grupos pensam durante alguns instantes e depois exprimem as suas ideias: "vai ficar em pó e depois vai desaparecer" (Bianca); “o açúcar vai desaparecer” (Rafael) ... (Diário de aula 2).

- Os grupos introduzem um objeto de cada vez numa bacia com água e observam o que acontece: "A madeira não afundou, está a flutuar" (Marta); "os outros acertamos todos" (Bianca); "o Pedro errou no lápis, porque ele disse que ia ao fundo mas ele flutua" (Tiago) (Diário de aula 1).

B4. Propor explicações para as observações e evidências obtidas. Exemplo:

- Solicito a um elemento de cada grupo que pressione a rolha, na vertical, e pergunto: "O que está a acontecer?" "A água faz a rolha vir sempre para cima, quando a largo" (Bruno). "Se carregar na rolha, ela vai ao fundo e depois vem para cima. A água faz a rolha não ir para baixo" (Carolina). "Então, quem é que a empurra para cima?" - Pergunto. "É a água" (vários). "A água "empurra" a rolha, não a deixa ficar no fundo" (Rita). "A água faz força para a rolha vir para cima" (Marta). (Diário de aula 1).

B5. Comunicar à turma as observações e teorias explicativas que emergem no interior do grupo. Exemplo:

- "Que significa, então um material solúvel? E insolúvel?" Grupo 1: "solúvel não se vê e insolúvel vê-se"; "o açúcar é solúvel e a areia é insolúvel"; Grupo 2: "insolúvel é uma coisa que nunca se dissolve e solúvel é uma coisa que se dissolve, mas fica na água em bocadinhos muito pequeninos e não se vê"; Grupo 3: "solúvel é o açúcar, porque deixamos de o ver, mas a água está doce. Insolúvel é a areia, porque continuamos a ver no copo, no fundo" (Diário de aula 2).

B6. Registar as aprendizagens realizadas (ver exemplos ilustrativos na figura 2 e 3 ). 


\section{Considerações finais}

A análise do diário de aula, sobre a "flutuação e afundamento de objetos em água", revela que crianças de 5/6 anos de idade são capazes de assumir um papel ativo e reflexivo nas atividades de aprendizagem, quando abordadas num contexto colaborativo de estimulação e liberdade de expressão do seu pensamento (VARELA, 2012a). No caso analisado, os alunos: a) começam por comunicar e representar, através do desenho, os significados pessoais que atribuem às palavras "flutuar" e "afundar"; c) elaboram depois previsões quanto à flutuabilidade de diferentes objetos em água, com base nesses significados construídos nas suas experiências pessoais; d) testam as previsões elaboradas; e) efetuam as correspondentes observações e classificam os objetos, de acordo com o critério flutua/afunda; f) tomam consciência da inconsistência das suas próprias ideias, quando confrontadas com situações que lhes são familiares e que contrariam a ideia do "peso", como único fator explicativo dos fenômenos de flutuação e afundamento dos objetos em água; g) inferem, através das observações realizadas, que a água exerce uma força, de baixo para cima, nos objetos - "a água empurra para cima" - e que essa força é menor do que o peso dos objetos, quando eles se afundam - "os que vão ao fundo têm mais força que a água"; g) procedem ao registo individual das aprendizagens realizadas.

Em todo este processo de aprendizagem, os significados que os alunos vão construindo, por via da interação física com os materiais e os objetos, são sujeitos a discussão e reflexão conjunta, em contexto de interação social (ALENAMY, 2000; IBÁÑEZ e ALEMANY, 2005). É na interação com os outros que as diferentes interpretações da experiência física são confrontadas, negociadas e reconstruídas (CANDELA, 1999), tendo em vista a construção de significados socialmente enriquecidos e partilhados por um número crescente de alunos. O professor, através de um "questionamento reflexivo", estimulador do pensamento e da ação dos alunos (SÁ, 2002a), vai sustentando e orientando a atividade cognitiva individual e coletiva dos alunos, ajudando-os a escalar progressivamente elevados níveis de aprendizagem. Tudo isto implica, conforme sustentam Sá (2002a) e Harlen (2004, 2007), um grande envolvimento pessoal e intelectual do aluno e é indissociável de uma intervenção intencionalmente orientada por parte do professor, com vista a promover, simultaneamente, nos alunos a construção de ideias mais concordantes com a realidade e o desenvolvimento de competências científicas.

Uma abordagem de ensino das ciências, baseada na experimentação, reflexão, comunicação e colaboração, exige, pois, ao professor e ao aluno renovados papéis em sala de aula (SÁ, 2002a; HARLEN, 2004). Neste sentido, foi possível identificar, neste estudo, um conjunto 
específico de ações relativas ao papel que os alunos e o professor desempenharam nessa perspectiva de abordagem das ciências. Assim, os alunos devem ter oportunidade de:

a) Comunicar e partilhar com os colegas e com o professor as suas ideias e modos de pensar, em relação às questões, fenômenos e situações problemáticas com as quais são confrontados. Segundo Sanmartí (2002) e Harlen (2007), a comunicação de ideias clarifica e melhora as próprias ideias e, consequentemente, a qualidade do pensamento; favorece a sua estruturação e ajuda o aluno a tomar consciência das incoerências das suas próprias ideias. Por outro lado, permite ao professor identificar as ideias iniciais dos alunos, para a partir delas promover o correspondente processo de ensino e aprendizagem (DRIVER, et al., 1999).

b) Trabalhar em grupo, partilhando, discutindo e confrontando ideias, experiências e estratégias com os outros, para que as aprendizagens sejam construídas coletivamente. Os contextos colaborativos de aprendizagem facilitam o aparecimento e o intercâmbio de diferentes ideias e interpretações explicativas das diversas situações de aprendizagem. A discussão que se gera no interior dos grupos, sob a influência conjunta dos seus pares e da ação do professor, possibilita aos alunos a tomada de consciência das suas próprias ideias e das ideias dos outros (VARELA, 2012a), assim como estimula a defesa de pontos de vista e a necessidade de os rever e/ou modificar (DOMÍNGUEZ e STIPCICH, 2009). Desse modo, os alunos não só partilham e avaliam criticamente as diversas explicações e justificações surgidas no interior dos grupos ou na turma, mas também aprendem, pela ação dos outros, a estruturar e a autorregular o seu pensamento (LARKIN, 2006).

c) Elaborar e testar previsões do resultado esperado, para que possam confrontar as suas ideias e teorias pessoais com as evidências (HARLEN e QUALTER, 2005). Segundo Sá (2002a), a elaboração fundamentada de previsões possibilita aos alunos tratar as suas teorias explicativas e a evidência como entidades distintas. Isto reforça não só o processo de contraste entre a evidência e a teoria, mas também ajuda a que a evidência tenha um maior impacto na estrutura mental da criança, favorecendo a revisão de ideias e teorias, nos casos em que a evidência as contraria.

d) Refletir e propor explicações fundamentadas nas observações e nos dados da evidência, de modo a avaliarem criticamente o grau de conformidade das suas ideias e expectativas com as evidências obtidas, tendo em vista uma progressiva coordenação e harmonização das novas teorias com o mundo físico-natural (KUHN, et al., 1988). Todavia, harmonizar as teorias com a evidência "não significa que toda a aprendizagem científica realizada pelos alunos exija ou seja suscetível de uma prova empírica atual; a reflexão mobilizadora de 
ideias e conhecimentos já adquiridos é, em si mesma, fonte de conhecimento" (SÁ e VARELA, 2004, p. 83). Trata-se, segundo os autores, de confirmar, refutar e/ou reformular ideias emergentes numa situação de aprendizagem, evocando experiências anteriores para que o aluno possa estabelecer o contraste de tais ideias com evidências do passado com que está familiarizado.

e) Comunicar à turma as observações, as teorias explicativas e as estratégias que emergem no interior dos grupos, para que estas sejam submetidas ao confronto crítico dos outros grupos ou da comunidade turma (SÁ e VARELA, 2007). O contexto de grande grupo deve alicerçarse numa dinâmica inter-grupos, dentro dos quais foram amadurecidas as condições para uma discussão e reflexão mais alargada de diferentes pontos de vista. Os momentos de discussão e argumentação em grande grupo constituem oportunidades para que todos os alunos beneficiem do trabalho desenvolvido por cada grupo, em particular. A responsabilidade de cada grupo apresentar o seu trabalho à turma promove o amadurecimento do trabalho dentro do grupo (Sá, 2002a).

f) Registar as aprendizagens realizadas. Os registos escritos ou iconográficos devem ser parte integrante do processo de exploração das atividades experimentais de ciências. Eles vão transformando as aprendizagens socialmente construídas em discurso individual interiorizado (VYGOTSKY, 1987). A escrita contribui para desenvolver a capacidade de pensar, na medida em que exige uma maior consciência das operações mentais que se executam (VYGOTSKY, 1987). Escrever implica pensar sobre o que é objeto da escrita, organizar as ideias, estabelecer relações entre elas, selecionar as melhores palavras e articulá-las adequadamente. Criar nos alunos o hábito regular de uma escrita, pessoalmente construída, a propósito das atividades experimentais, é dar continuidade ao processo reflexivo e é promover no aluno o mais elevado grau de aprendizagem que está ao seu alcance, em cada tópico em estudo (SÁ e VARELA, 2007). Por outro lado, os registos dos alunos permitem, ao professor, obter indicações sobre o nível de aprendizagem que vão alcançando individualmente, as suas dificuldades ou incompreensões e prestar ajudas individualizadas em função das necessidades específicas de cada aluno.

Todo este conjunto de ações assumido pelos alunos é interdependente da atuação do professor, o qual deve, por sua vez: a) identificar as ideias iniciais dos alunos; b) incentivar os alunos a elaborar previsões; $c$ ) proporcionar aos alunos a oportunidade de testar as suas ideias e previsões; d) fornecer os recursos materiais a serem utilizados pelos alunos; e) promover a colaboração e estimular a interação entre os alunos no interior dos grupos; f) colocar questões 
que estimulem do pensamento dos alunos; g) promover a comunicação à turma do trabalho desenvolvido pelos grupos; h) avaliar as aprendizagens realizadas pelos alunos.

Estas ações identificadas através da análise dos diários de aula, não esgotam o papel do professor e dos alunos no processo de ensino experimental das ciências. Tratam-se apenas de ações presentes na análise de 4 aulas. Outras aulas, que abordem outros temas curriculares de ciências, implicarão certamente a mobilização e utilização de outras ações, estratégias, recursos materiais e cognitivos. Porém, os resultados apresentados neste artigo constituem importantes elementos, devidamente ilustrados, de apoio à ação educativa do professor, com vista à promoção de uma prática renovada no ensino das ciências nos primeiros níveis de escolaridade. 


\section{Referências}

Alemany, I. G. Bases teóricas de una propuesta didática para favorecer la comunicación en el aula. In J. Jorba, et al.,. Hablar y escribir para aprender. Uso de la lengua en situación de enseñanzaaprendizaje desde las áreas curriculares (p. 19-27). Madrid: Editorial Sintesis, 2000.

Candela, A. Ciencia en el aula. Los alumnos entre la argumentación y el consenso. México: Editorial Paidós, 1999.

Chin, C. Classroom Interaction in Science: Teacher questioning and feedback to students' responses. International Journal of Science Education, v. 28, n. 1, p. 1315-1346, 2006.

Domínguez, M. A.; Stipcich, M. S. Buscando indicadores de la negociación de significados en clases de Ciencias Naturales. Revista Electrónica de Enseñanza de las Ciencias, v.8 , n. 2, p. 539-551, 2009. Disponível em: http://www.saum.uvigo.es/reec/

Driver, R.; Guesne, E.; Tiberghien, A. (1999). Ideas científicas en la infancia y la adolescencia (4a ed.). Madrid: Ediciones Morata, 1999.

Harlen, W. Enseñanza y aprendizaje de las ciencias. Madrid: Ediciones Morata, 2007.

Harlen, W. \& Qualter, A. The Teaching of Science in Primary Schools. London: David Fulton Publishers, 2005.

Harlen, W. Evaluating Inquiry-Based Science Developments. A Paper Commissioned by the National Research Council in Preparation for a Meeting on the Status of Evaluation of InquiryBased Science Education. National Academy of Sciences, 2004. Disponível em: http://www.nsrconline.org/pdf/nas_paper_eval_inquiry_science.pdf

Ibáñez, V. E.; Alemany, I. G. La interacción y la regulación de los procesos de enseñanzaaprendizaje en la clase de ciencias: análisis de una experiencia. Enseñanza de Las Ciencias, v. 23, n. 1, p. 97-110, 2005.

Kuhn, D.; Amsel, E.; O'Loughlin, M. The development of scientific thinking skills. Orlando, FL: Academic Press, 1988.

Larkin, S. Collaborative Group Work and Individual Development of Metacognition in the Early Years. Research in Science Education, v. 36, p. 7-27, 2006.

Latorre, A. La investigación-acción. Conocer y cambiar la práctica educativa. Barcelona: Editorial Graó, 2004.

Martínez, J. M. O.; Díaz, J. A. A. La enseñanza de las ciencias en primaria y secundaria hoy. Algunas propuestas de futuro. Revista Eureka sobre Enseñanza y Divulgación de las Ciencias, v. 2, n. 2, p. 241-250, 2005. Disponível em: http://www.redalyc.org/pdf/920/92020210.pdf

Mason, L. Introduction: Bridging the Cognitive and Sociocultural Approaches in Research on Conceptual Change: Is it Feasible? Educational Psychologist, v. 42, n. 1, p. 1-7, 2007.

Mauri, T. O que é que faz com que o aluno e a aluna aprendam os conteúdos escolares? In C. Coll, et al., (Eds.). $\mathbf{O}$ construtivismo na sala de aula. Novas perspectivas para a ação pedagógica ( $p$. 74-119). Porto: Edições ASA, 2001.

Ministério da educação - ME. Organização Curricular e programas Ensino Básico - 10 Ciclo. Mem Martins. Ministério da Educação. Departamento de Educação Básica, 2004.

Molenaar, I.; van Boxtel, C. A.; Sleegers, P. J. C. Metacognitive scaffolding in an innovative learning arrangement. Instructional Science, v. 39, p. 785-803, 2011. 
Naylor, S.; Keogh, B.; Downing, B. Argumentation and Primary Science. Research in Science Education, v. 37, pp. 17-39, 2007.

Onrubia, J. Ensinar: criar Zonas de Desenvolvimento Próximo e intervir nelas. In C. Coll et al., (Eds.). O construtivismo na sala de aula: Novas perspectivas para a acção pedagógica (p. 120149) Porto: Edições ASA, 2001.

Pérez Gómez, A. I. Comprender y transformar la enseñanza. Madrid: Ediciones Morata,S. L., p. 17-137, 2005.

Pozo, J. I.; Crespo, M. A. G. Aprender y Enseñar Ciencia. Madrid: Ediciones Morata, S. L., 2006.

Sá, J.; Carvalho, G. (1997); Ensino Experimental de Ciências. Definir uma Estratégia para o 10 Ciclo. Braga: Editora Correio do Minho, 1997.

Sá, J. Diary Writing: An Interpretative Research Method of Teaching and Learning. Educational Research and Evaluation, v. 8, n. 2, p. 149-168, 2002b.

Sá, J. Renovar as Práticos no 10 Ciclo Pela Via das Ciências da Natureza. Porto: Porto Editora, 2002a.

Sá, J.; Varela, P. Crianças Aprendem a Pensar Ciências: uma abordagem interdisciplinar. Porto: Porto Editora, 2004.

Sá, J.; Varela, P. Das Ciências Experimentais à Literacia: Uma proposta didática para o 10 ciclo. Porto: Porto Editora, 2007.

Sanmartí, N. Un reto: mejorar la enseñanza de las ciencias. In Catalá, et al., (Eds.). Las ciencias en la escuela. Teorías y prácticas (p. 13-26). Barcelona: Editorial Gráo, 2002.

Solé, I.; Coll, C. Os professores e a conceção construtivista. In C. Coll, et al., (Eds.). 0 construtivismo na sala de aula. Novas perspectivas para a ação pedagógica (p. 8-27). Porto: Edições ASA, 2001.

Varela, P. Experimental Science Teaching in Primary School: Reflective Construction of Meanings and Promotion of Transversal Skills. Saarbrücken, Germany: Lap Lambert Academic Publishing, 2012a.

Varela, P. The reflective experimental construction of meanings about the shape of the Earth and the alternation of day and night. International Electronic Journal of Elementary Education, v. 5, n. 1, p. 5-26, 2012b. Disponível em: http://www.iejee.com/5_1_2012/IEJEE_5_1_5_26.pdf

Vosniadou, S.; Skopeliti, I.; Ikospentaki, K. Reconsidering the role of artifacts in reasoning: Children's understanding of the globe as a model of the earth. Learning and Instruction, n. 15, p. 333-351, 2005.

Vygotsky, L. S. A Formação Social da Mente. O Desenvolvimento das Processos Psicológicos Superiores. São Paulo: Martins Fontes, 1998.

Vygotsky, L. S. Pensamento e Linguagem. São Paulo: Martins Fontes Editora, 1987.

Zabalza, M. A. Diarios de clase: un instrumento de investigación. Madrid: Narcea, 2004.

Paulo Varela: Professor Auxiliar do Instituto de Educação da Universidade do Minho e

R. B. E. C. T., vol 6, núm. 2, mai-ago.2013 ISSN - 1982-873X 
investigador do Centro de Investigação em Estudos da Criança - CIEC. pibvarela@ie.uminho.pt Ana Patrícia Martins: Mestre em Educação Pré-escolar e 10 Ciclo do Ensino Básico.

patriciamartins_89@hotmail.com 